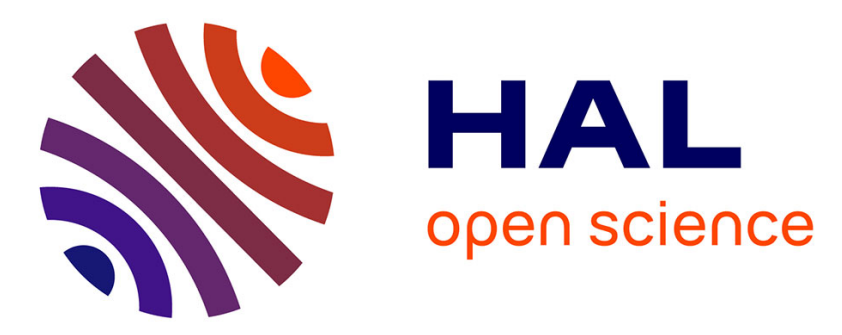

\title{
Time variations of land water storage from an inversion of 2 year of GRACE geoids
}

Guillaume Ramillien, Frédéric Frappart, Anny Cazenave, Andreas Güntner

\section{To cite this version:}

Guillaume Ramillien, Frédéric Frappart, Anny Cazenave, Andreas Güntner. Time variations of land water storage from an inversion of 2 year of GRACE geoids. Earth and Planetary Science Letters, 2005, 235, pp.283-301. 10.1016/j.epsl.2005.04.005 . hal-00280248

\section{HAL Id: hal-00280248 \\ https://hal.science/hal-00280248}

Submitted on 5 Nov 2009

HAL is a multi-disciplinary open access archive for the deposit and dissemination of scientific research documents, whether they are published or not. The documents may come from teaching and research institutions in France or abroad, or from public or private research centers.
L'archive ouverte pluridisciplinaire HAL, est destinée au dépôt et à la diffusion de documents scientifiques de niveau recherche, publiés ou non, émanant des établissements d'enseignement et de recherche français ou étrangers, des laboratoires publics ou privés. 
Figure 1

AVAILABLE MONTHLY GRACE GEOIDS FROM CSR

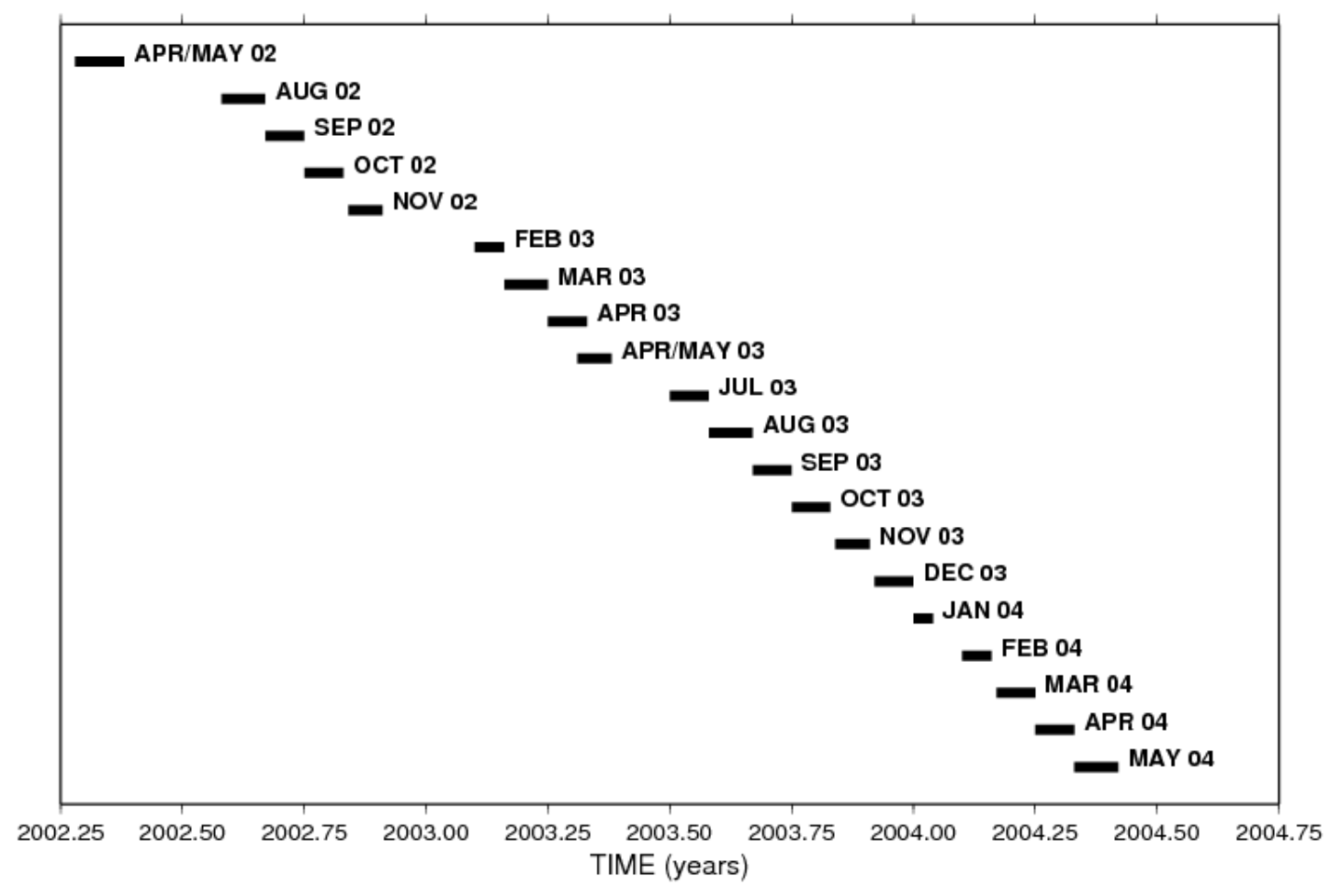


Figure 2

GRACE IW SOLUTION _.. APF 2003 -.- DEG-25-30
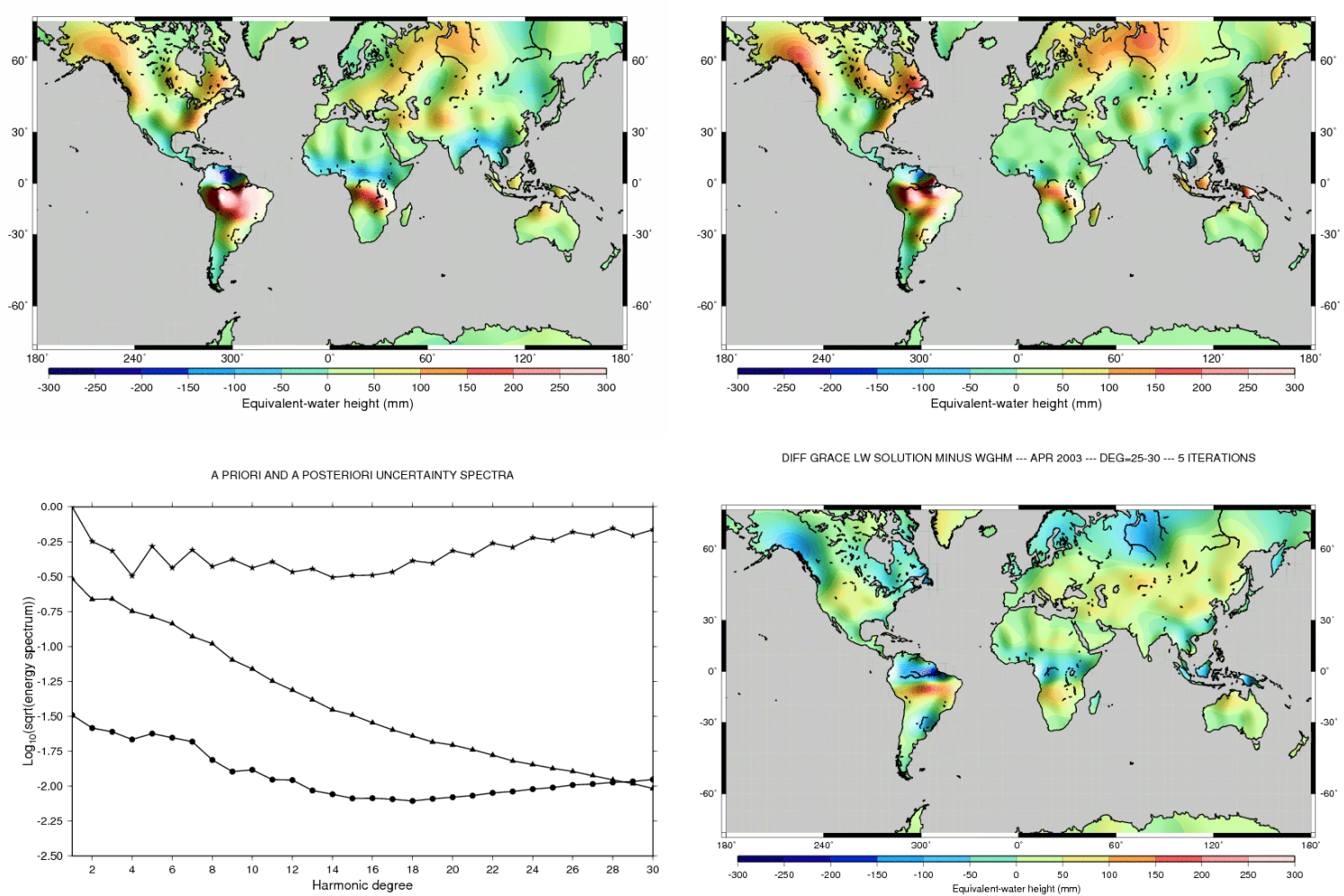

GEOID RESIDUALS -- APR 2003 --.- DEG-25-30

GRACE LW SOLUTION … APR 2003 -.. DEG-25-30 -.. 10 ITERATIONS
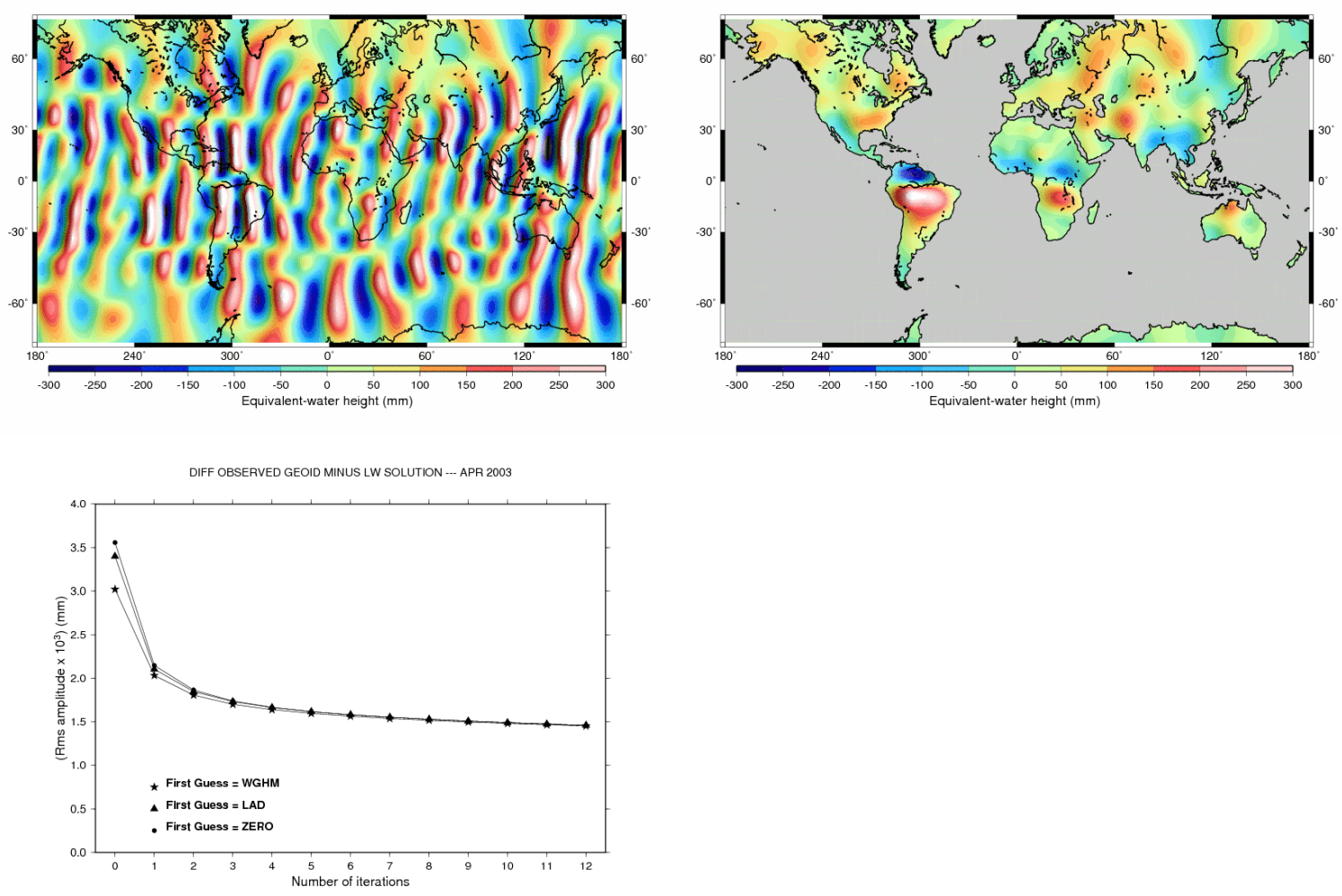
Figure 3

GRACE SOLUTION --- SURF W + SOIL W + GW --- APR 2003 --- DEG=25-30 --- 5 ITERATIONS

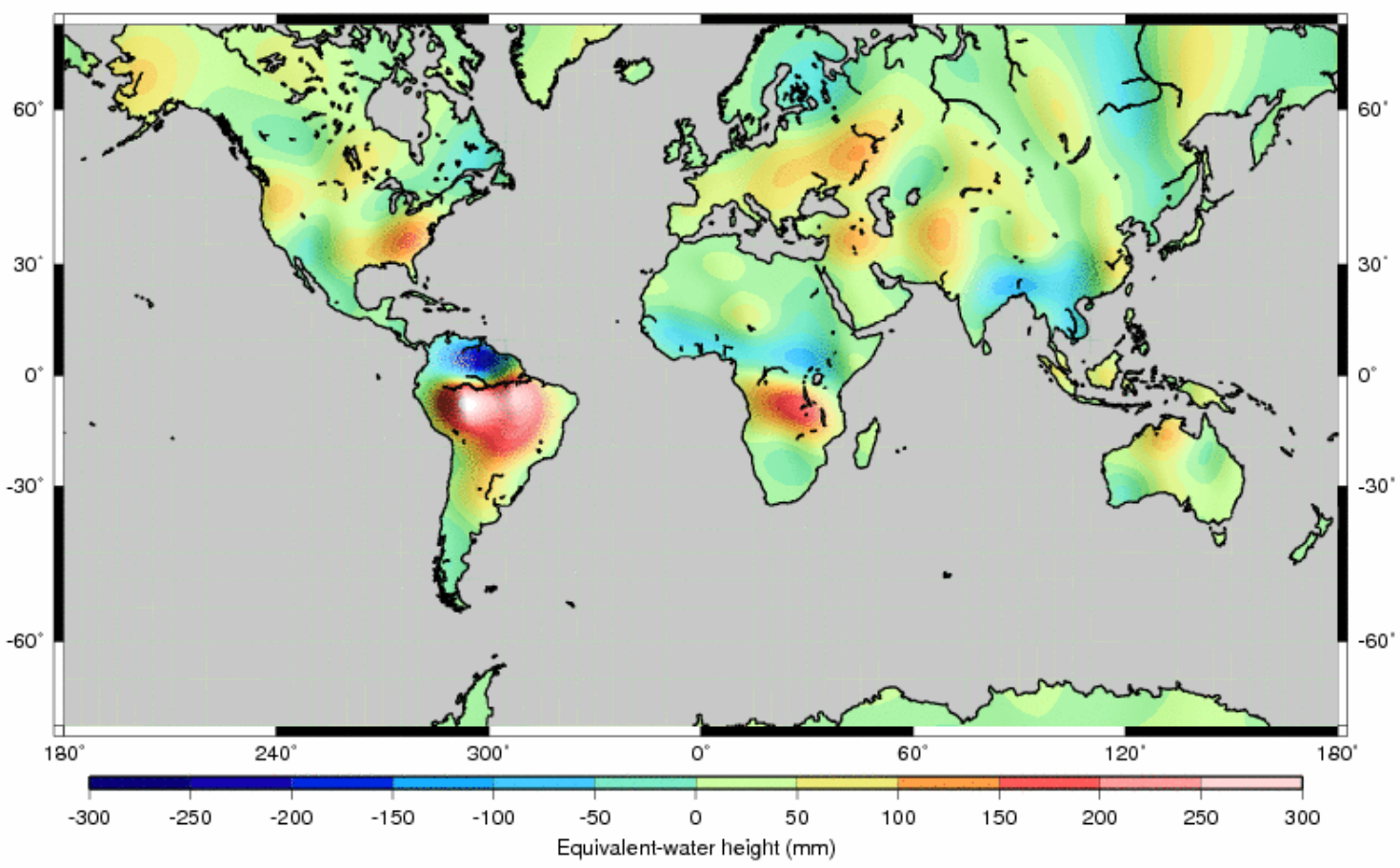

GRACE SOLUTION --- SNOW --- APR 2003 --- DEG=25-30 --- 5 ITERATIONS

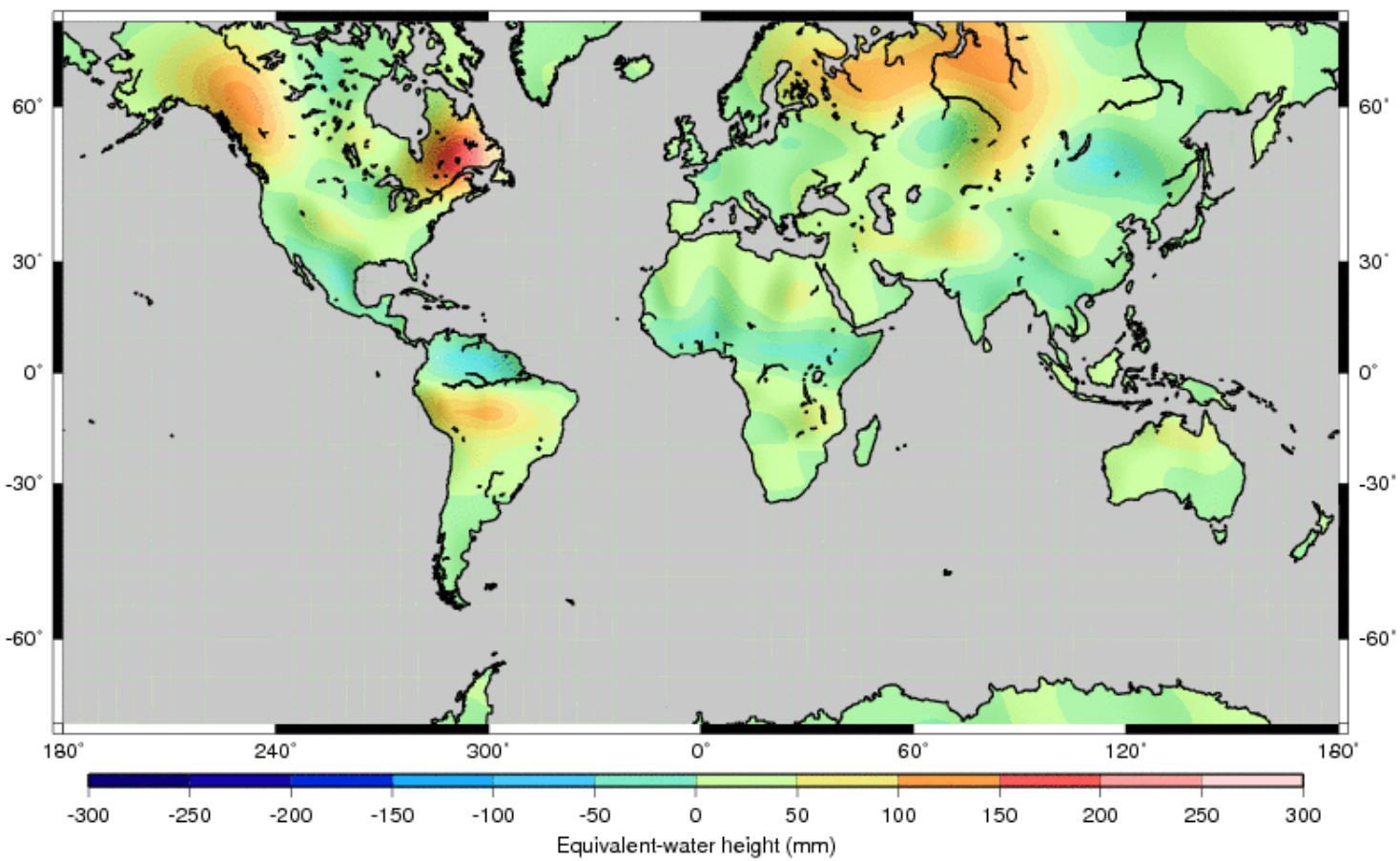


Figure 4

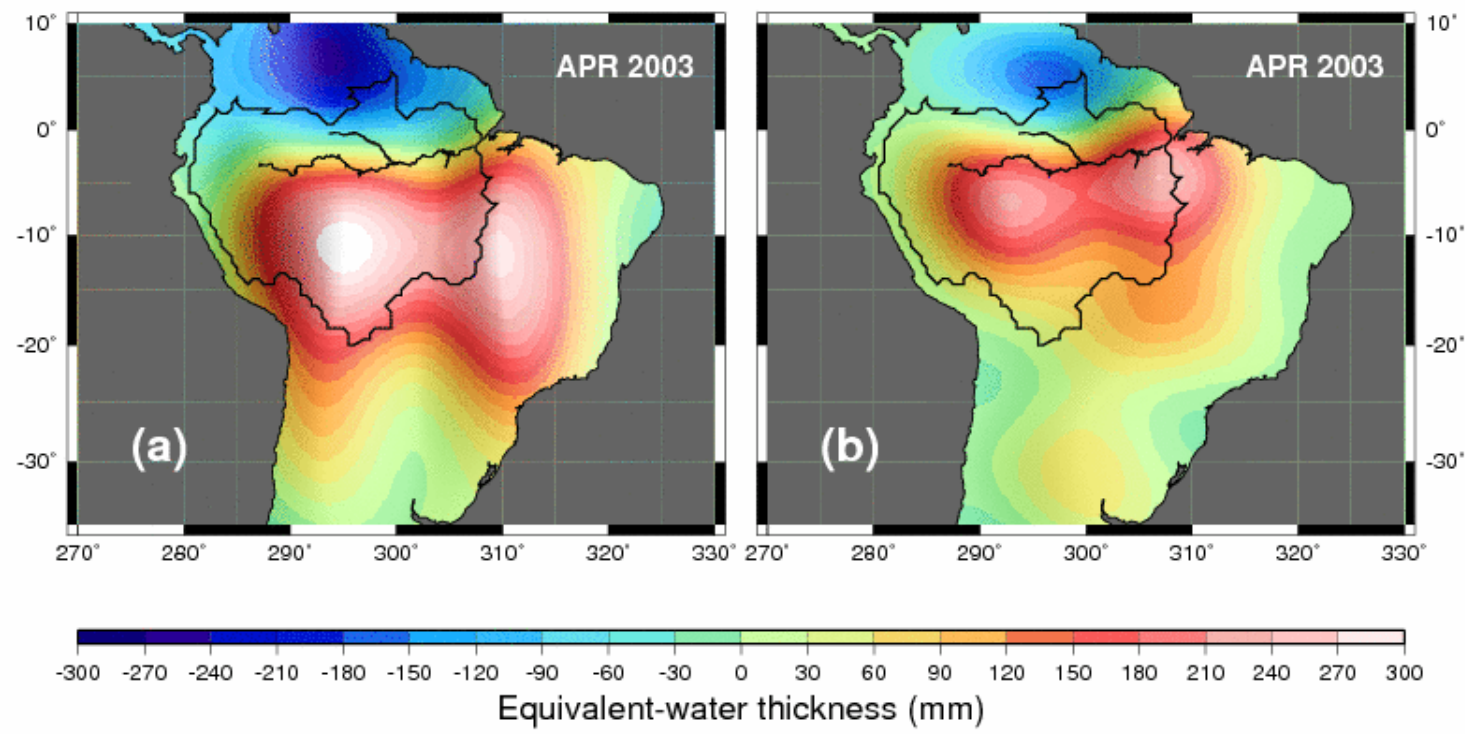


Figure 5
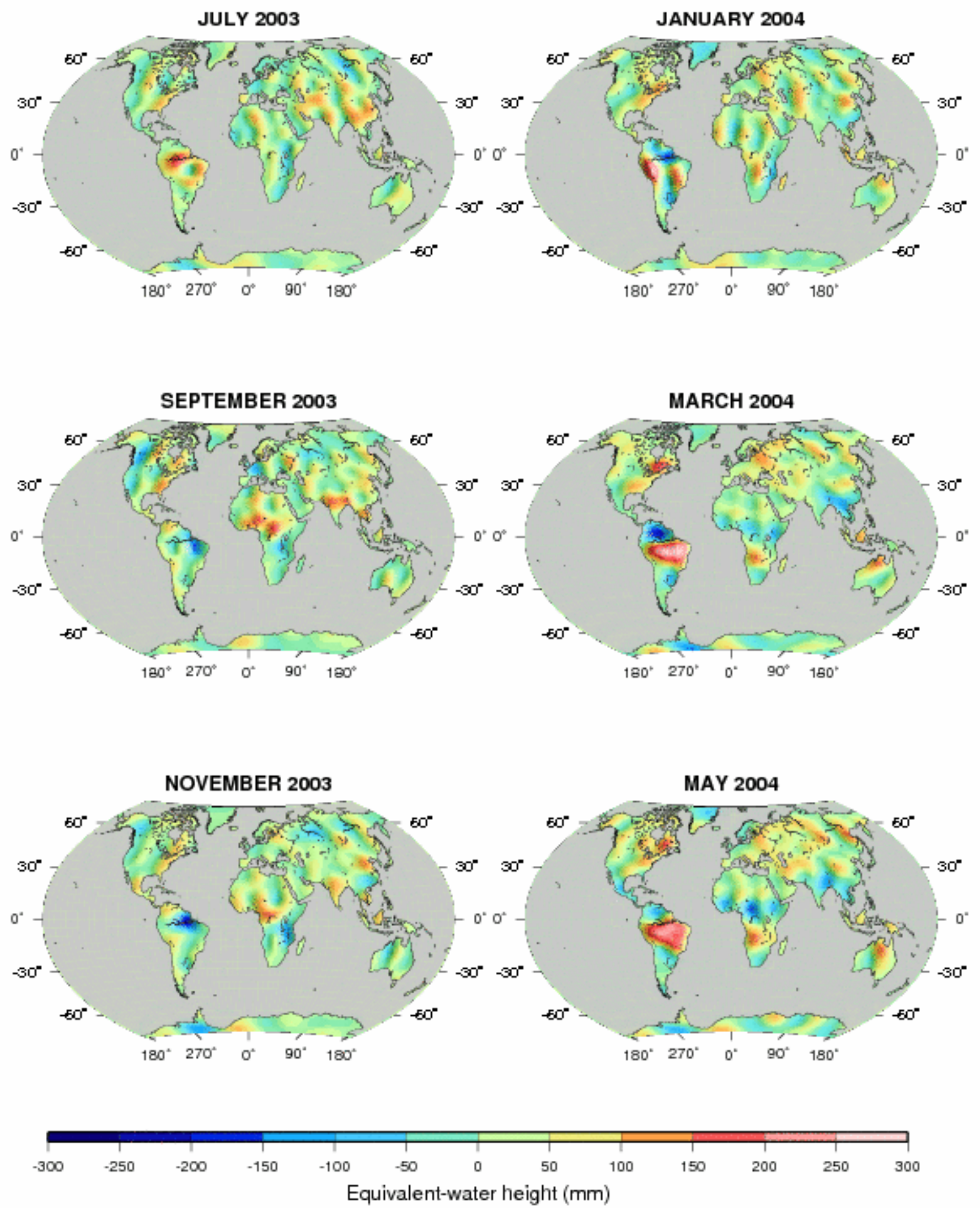
Figure 6

SEASONAL AMPLITUDE --- GRACE LW --- 5 ITERATIONS

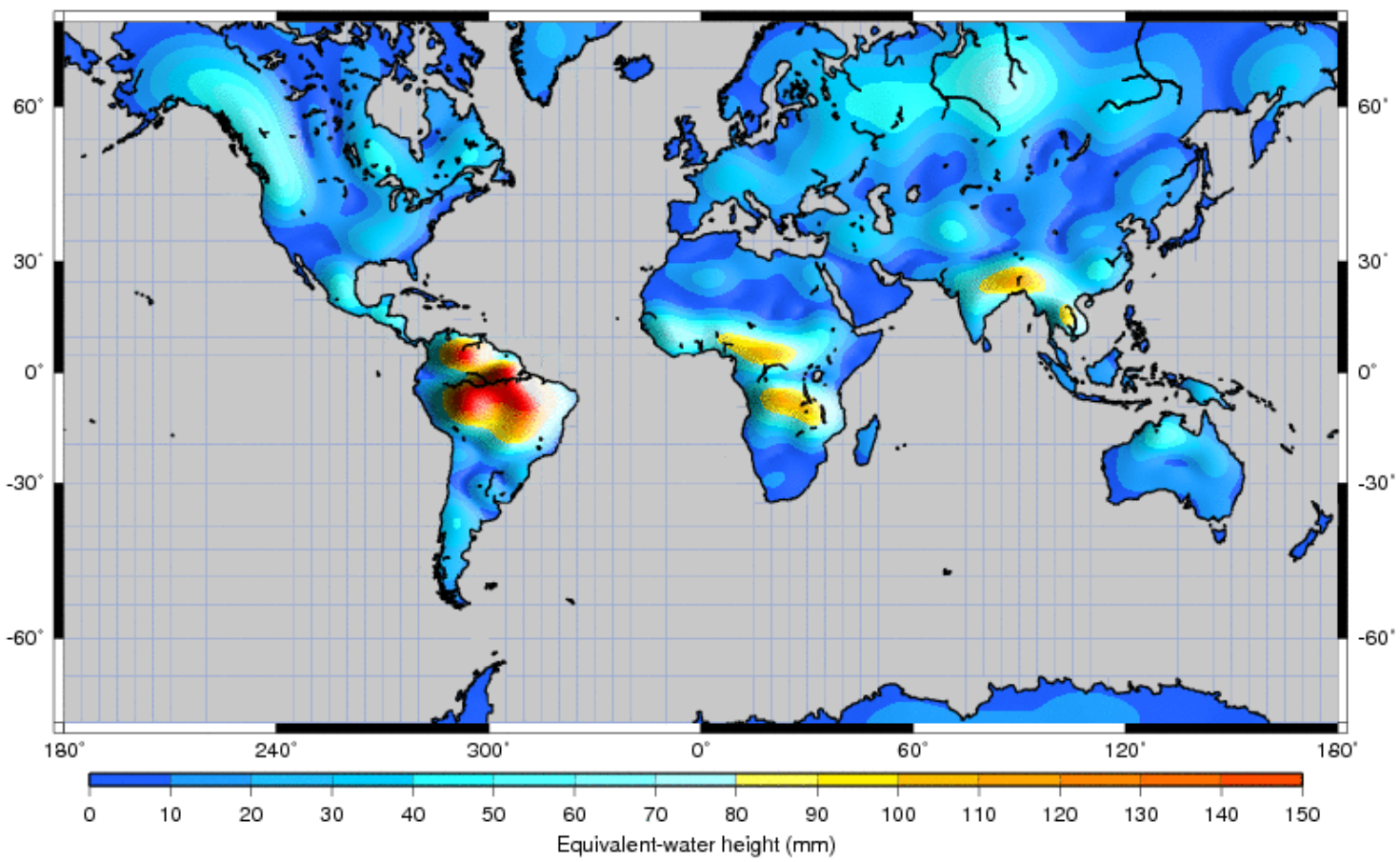

SEASONAL AMPLITUDE --- WGHM

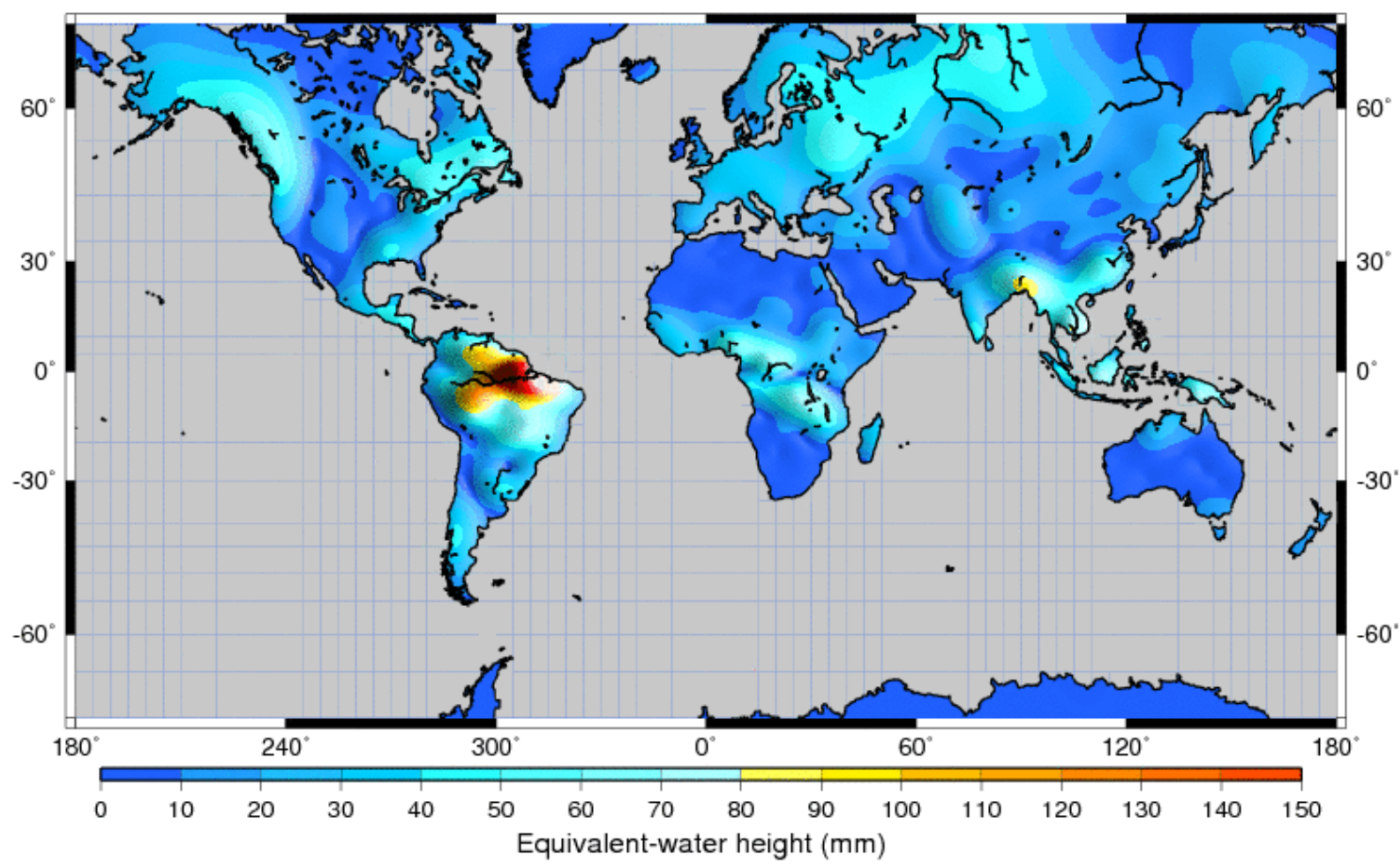


Figure 7

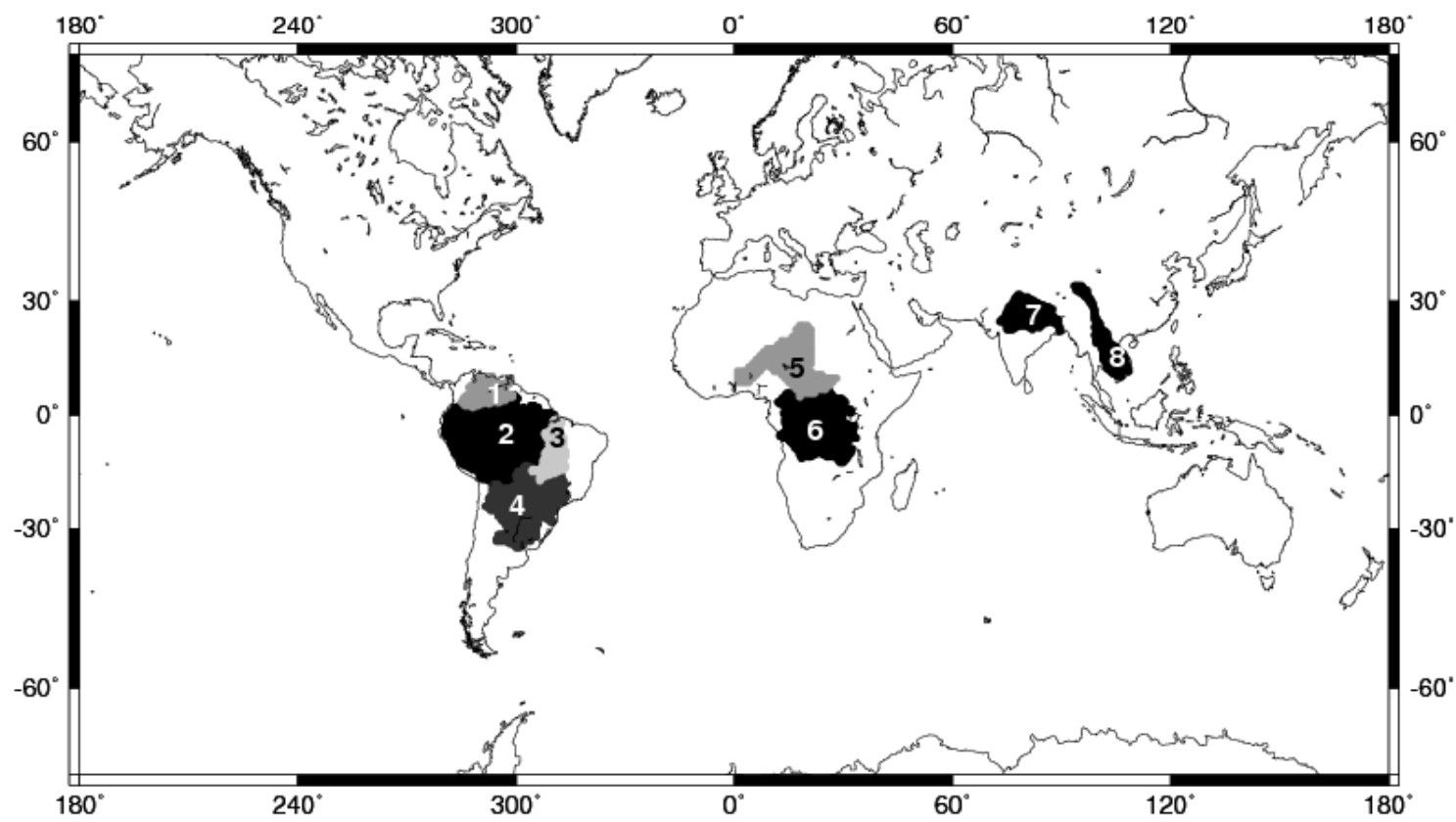


Figure 8
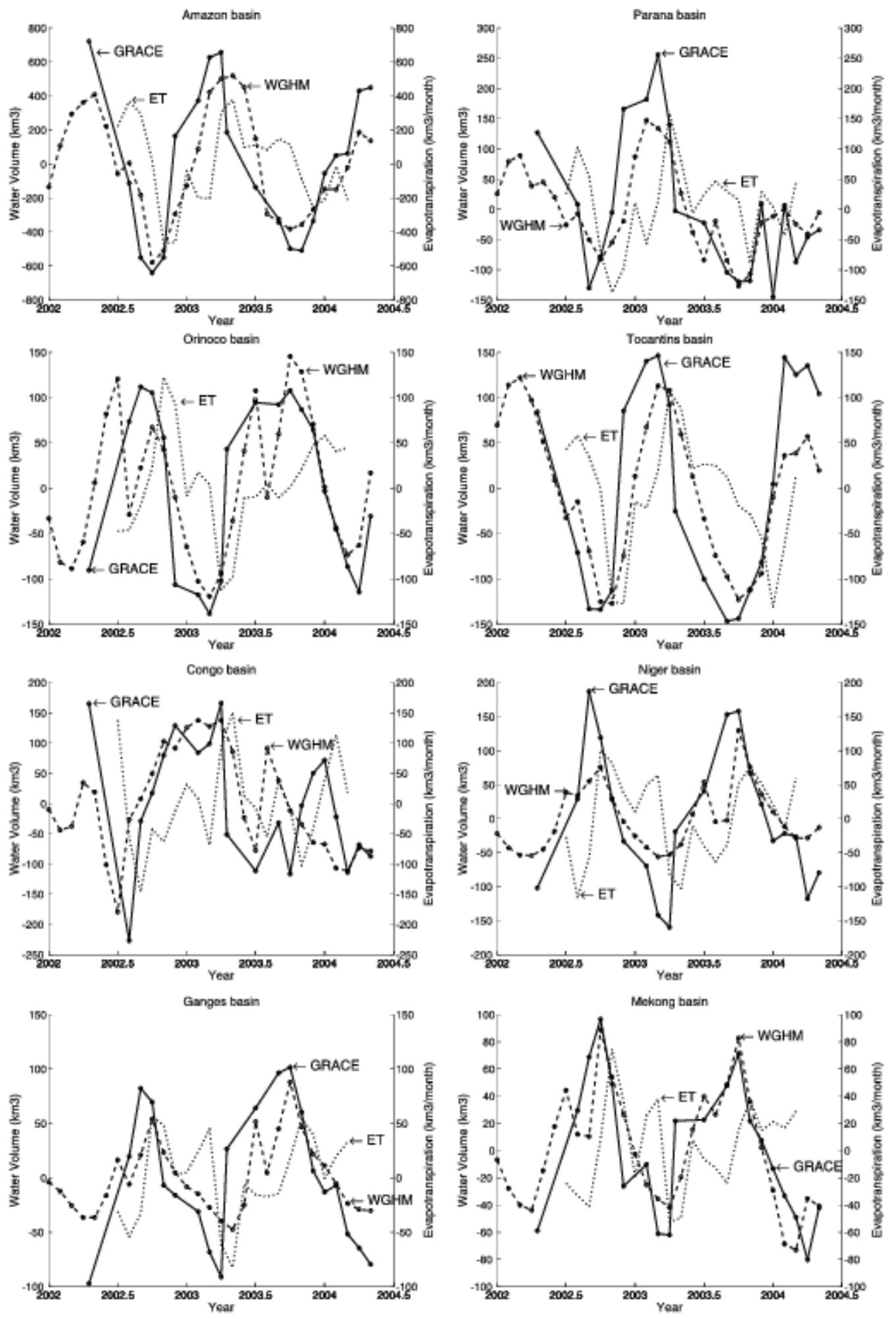